\title{
Extra-high oxygen addition as a new strengthening strategy to overcome strength/ductility trade-off in fully biocompatible hexagonal titanium alloys.
}

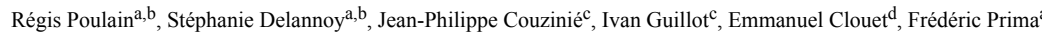

a : PSL Research University, Chimie ParisTech-CNRS, Institut de recherche de Chimie Paris (UMR 8247), 75005 Paris, France

b : Biotech Dental SAS, Salon-de-Provence

c : Université Paris Est, ICMPE (UMR 7182) CNRS-UPEC, 2-8 rue Henri Dunant, F- 94320 Thiais France

d : DEN-Service de Recherches de Métallurgie Physique, CEA, Université Paris-Saclay, F-91191 Gif-sur-Yvette, France

\section{Abstract}

A new titanium alloy family was developed aiming at creating a fully biocompatible alternative to titanium alloys currently on the dental implants market. Despite their hexagonal closepacked (HCP) single-phase structure, these Ti-Zr-O materials display an extremely interesting combination of properties. Zirconium is shown to be involved through a double contribution: on the one hand, a moderate but noticeable solid solution strengthening effect and on the other hand, a strong grain refinement. Therefore, the combination of both effects results in a beneficial strengthening of Ti-Zr-O alloys. However, the main remarkable aspect remains the outstanding hardening generated by extra high oxygen addition, occurring without any drop of ductility. The evolution of the dislocation network according to the oxygen content has been investigated to understand the underlying mechanisms in these Ti-Zr-O alloys, allowing to overcome the classical strength/ductility trade-off in commercial titanium alloys. Finally, the different perspectives of these findings in the field of biomedical and more generally in the field of titanium alloys are discussed.

\section{Introduction}

Thanks to an excellent combination of properties such as biocompatibility or corrosion resistance, the use of titanium in dental implants has become predominant in modern dentistry. However, the Ti-6Al-4V (TA6V), one of the most used alloys in this field, is more and more contested on the assumption that vanadium may display long-term detrimental cytotoxic effects [1-2], and that aluminium could play a role in the appearance of neurodegenerative diseases as Alzheimer in treated patients [3]. The current study aims to present a new fully biocompatible titanium alloy family specially designed for dental applications.

Among the most biocompatible metals, zirconium provides the advantages of being also one of the most resistant with respect to corrosion [4] and of being miscible in any proportion with titanium [5]. Hence, solid solution strengthening could be obtained while preserving the ductile HCP phase of titanium. It should be noted that the zirconium should not exceed $10 \mathrm{wt} \%$ to maintain the Young's modulus as low as possible and thus promote osseointegration [6]. Nevertheless, the strength of such a matrix is not expected to be high enough to reach the values of reference materials such as TA6V. Therefore, the strengthening of the Ti-Zr binary is brought by the introduction of interstitials such as oxygen: cost-effective, light and presenting no risk for healthcare. Although oxygen has been blamed, for decades, for its severe embrittling effect on titanium [7-10], several research works have since showed that this approach could be successful [11-13]. Still, the use of oxygen as an alloying element is quite innovative and opens an interesting insight for the titanium industry.

In this study, the microstructure and tensile properties of this new alloy family has been investigated with a special attention given to the role of oxygen on active deformation mechanisms.

\section{Material and experiments}

Ti-Zr-O buttons of 200g were fabricated by TIMET UK from pure titanium and zirconium sponges, and oxygen was added in a controlled way through a solid-state process (i.e. using powder particles of $\mathrm{TiO}_{2}$ ) during the melting. Ingots were then hot-rolled and annealed at $650^{\circ} \mathrm{C}$ for 30 minutes. Nominal compositions and actual interstitials contents assessed by gas analyses are listed in Table 1 (C, $\mathrm{H}$ and $\mathrm{Fe}$ contents were found to be less than $60 \mathrm{ppm})$. As-received ingots were cold-rolled down to $0.6 \mathrm{~mm}$ sheets with a reduction level of $40 \%$ or $85 \%$ depending on their coldworkability (as shown in table 1$)$.

Table 1: Summary of studied alloys. The analysed interstitials contents and the thickness reduction applied by cold-rolling are specified for each composition.

\begin{tabular}{|c|c|c|c|}
\hline \multirow{2}{*}{$\begin{array}{l}\text { Alloys Designation } \\
\text { (Contents in wt\%) }\end{array}$} & \multicolumn{2}{|c|}{$\begin{array}{c}\text { Interstitial Elements } \\
(\text { Content in wt\%) }\end{array}$} & \multirow{2}{*}{$\begin{array}{l}\text { Thicness Reduction } \\
\text { by cold-rolling (\%) }\end{array}$} \\
\hline & (O & $\overline{\mathbf{N}}$ & \\
\hline $\mathrm{Ti}-4.5 \mathrm{Zr}-0.15 \mathrm{O}$ & 0.147 & 0.004 & 85 \\
\hline $\mathrm{Ti}-4.5 \mathrm{Zr}-0.250$ & 0.242 & 0.003 & 85 \\
\hline $\mathrm{Ti}-4.5 \mathrm{Zr}-0.4 \mathrm{O}$ & 0.374 & 0.010 & 85 \\
\hline $\mathrm{Ti}-4.5 \mathrm{Zr}-0.6 \mathrm{O}$ & 0.561 & 0.003 & 40 \\
\hline $\mathrm{Ti}-4.5 \mathrm{Zr}-0.80$ & 0.835 & 0.003 & 40 \\
\hline Ti - 0.40 & 0.392 & 0.007 & 40 \\
\hline $\mathrm{Ti}-9 \mathrm{Zr}-0.4 \mathrm{O}$ & 0.389 & 0.008 & 40 \\
\hline
\end{tabular}

The metal sheets were subsequently recrystallized in pre-heated molten carbonate baths at $750^{\circ} \mathrm{C}$ for $600 \mathrm{~s}$ and water quenched. Electron Backscatter Diffraction (EBSD) studies were carried out in a ZEISS GEMINI field emission gun scanning electron microscope (FEG-SEM) operating at 20kV. Prior to EBSD observations, samples were electropolished using a solution of 59\% 2butoxyethanol, $33 \% \mathrm{CH}_{3} \mathrm{OH}, 6 \% \mathrm{HClO}_{4}$ and $2 \% \mathrm{HCl}$. Flat tensile specimens were machined along the rolling direction and then tested with an INSTRON 5966 tensile machine at room temperature at a strain rate of $10^{-3} \mathrm{~s}^{-1}$. A $10 \mathrm{~mm}$ gauge length extensometer was used for direct strain measurement. Slices of the tensile samples were taken parallel to the tensile axis and mechanically polished up to $100 \mu \mathrm{m}$ of thickness. Thin foil specimens were prepared with a twin-jet electropolishing apparatus using a solution of methanol, butan-2-ol and perchloric acid (10:6:1 volume ratio), at $19 \mathrm{~V}$ and with a temperature between -25 and $-13^{\circ} \mathrm{C}$. The thin foils were examined with a JEOL $2000 \mathrm{EX}$ electron microscope operating at $200 \mathrm{kV}$.

\section{Results and discussion}

Microstructure's sensitivity to alloying elements

The evolution of EBSD mapping of recrystallised samples according to zirconium content is displayed along the rolling direction (RD) on figure 1. All alloys exhibit a single HCP phase composed of equiaxed grains. The microstructure is highly textured and present the expected orientation for $\alpha$ titanium submitted to cold rolling followed by recrystallization treatment along RD [14]. However, the grain size is revealed to be very sensitive to the alloy composition (figure 1.d). 


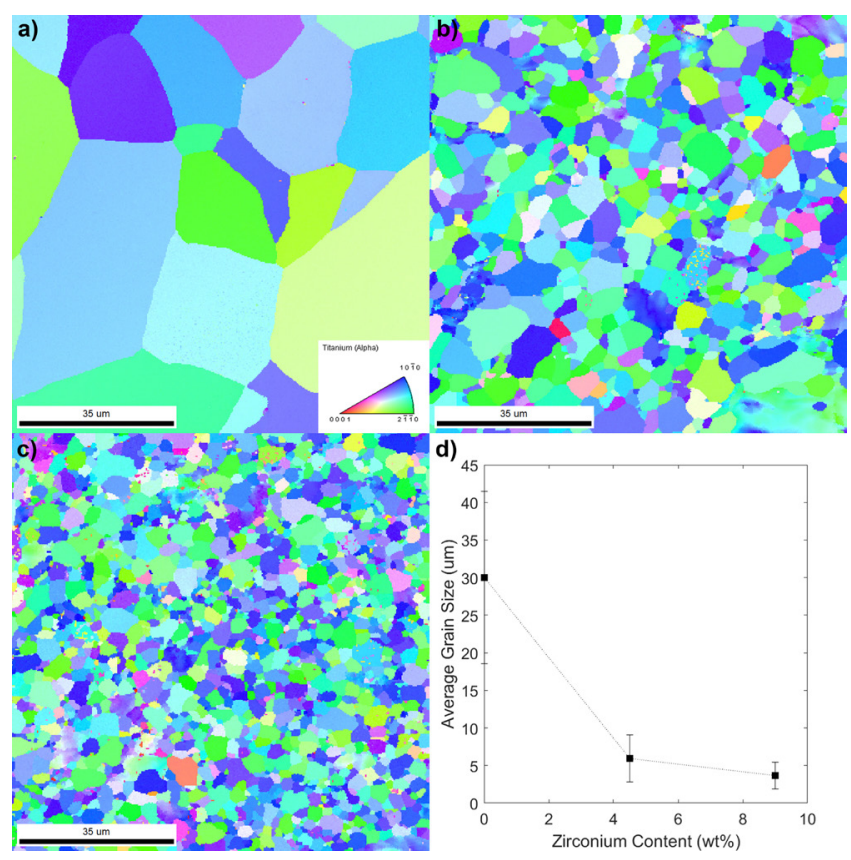

Figure 1: EBSD mapping of Ti-X\%Zr-0.4\% with X=0, 4.5 or 9 ((a), (b), (c) respectively) in recrystallised state and along $R D$. (d) represents the grain size evolution according to Zr content. (b) is representative of Ti$4.5 \% \mathrm{Z}$ - Y\%O microstructure $(Y=0.15$ to 0.8$)$

Hence, a ratio of 1:6 can be noticed with the addition of $\mathrm{Zr}$, leading to a reduction of the average grain size from 30 to $5 \mu \mathrm{m}$. Still, further increase in $\mathrm{Zr}$ content does not lead to significant grain size decrease. This phenomenon was evidenced by Matayshi \& al [15] in Ti-Zr alloys and seems to arise from a zirconium segregation at the grain boundaries (GB). This "solute drag effect" would lead to GB pinning and prevent grain coarsening even during heat treatment at high temperature.

The figure $1 . \mathrm{b}$ is representative of the microstructure of all Ti-4.5\% $\mathrm{Zr}-\mathrm{X} \% \mathrm{O}$ alloys (with $\mathrm{X}=0.15-0.8 \%$ ). It is worth noting that the grain size and the texture stay unchanged with $\mathrm{O}$ addition, regardless the thickness reduction applied. Eventually, in accordance with the known solubility limit of oxygen in HCP titanium $[10,15,16]$, no other phase is evidenced on recrystallized states, even in oxygen-rich materials.

Contributions of the alloying elements to the tensile properties

The uniaxial tensile behaviour of the Ti-Zr-O alloys is plotted on figure 2.a and 2.b according to zirconium and oxygen contents, respectively. At first sight, it can be noticed that both exhibit enhanced yield strength and mechanical resistance with increasing alloying element content. The yield stress evolution with respect to substitutional concentration is found to increase of about $33 \mathrm{MPa}$ per $1 \mathrm{wt} \% \mathrm{Zr}$ addition. This increase is believed to originate from two major factors. The first one is the Hall-Petch effect as a result of the grain size reduction from 30 to $3 \mu \mathrm{m}$ due to some "solute-drag effect". Nevertheless, Medvedev et al. [18] assessed that such a grain size decrease in Ti-Zr alloys could not be responsible for a rise of the yield strength of more than 80MPa. Thus, the solid solution effect shall account as a complementary contribution to the observed strengthening. However, those two effects are accompanied by a slight deterioration in ductility at higher zirconium content, as stated in the literature [18-19]. This trend justified maintaining $\mathrm{Zr}$ content as low as $4.5 \mathrm{wt} \%$ for the other Ti-Zr-O alloys for optimized strength/ductility combination.
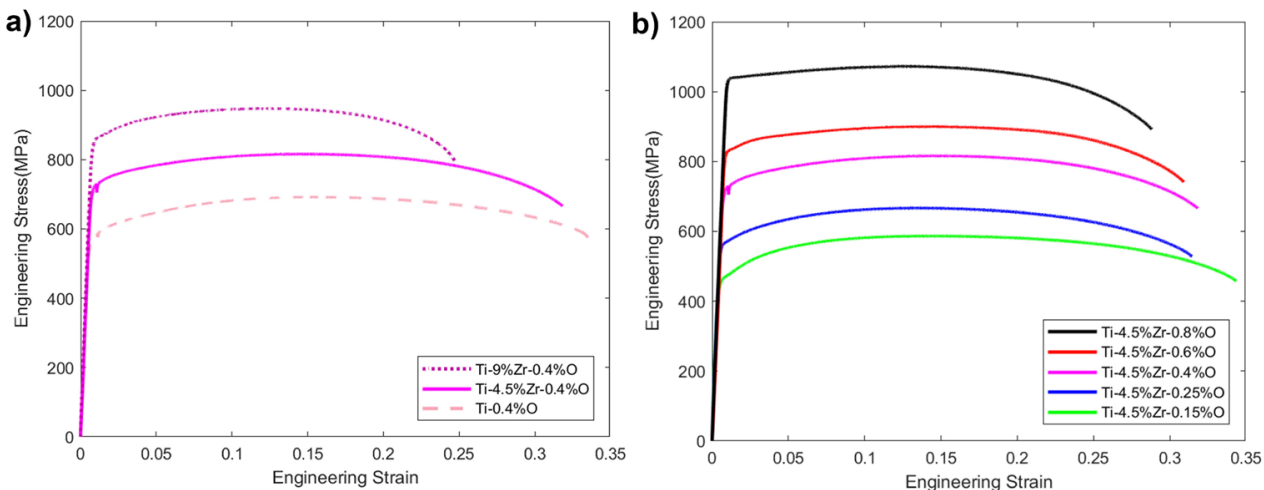

Figure 2: Evolution of tensile properties of TiZrO alloys according to Zr content (a) (wt\%O fixed at 0.4) and according to O content (b) (wt\% Zr fixed at 4.5). Materials were tested at room temperature at a strain rate of $10^{-3} s^{-1}$

As expected, the strengthening effect of oxygen is shown to be much higher compared to the one of zirconium. Indeed, with a drastic yield strength increase of around $100 \mathrm{MPa}$ for $0.1 \mathrm{wt} \% \mathrm{O}$ (consistent with the values stated in the literature for $\mathrm{O}$ addition in pure $\mathrm{Ti}$ [12-13]), the hardening potential of the interstitial element is thirty times stronger than zirconium in TiZrO alloys. Surprisingly, and in contrast with Ti-O based systems, unrepresentative ductility loss has been witnessed, despite extra-high oxygen contents up to $0.8 \mathrm{wt} \%$. As a result, a promising combination of mechanical properties can be reached in the Ti-4.5Zr- $0.8 \mathrm{O}$ alloy, displaying a UTS value of $1075 \mathrm{MPa}$ combined with a total elongation of $28 \%$ at fracture. It may be noted that this level of ductility has been hardly obtained, in "high-strength" titanium alloys (over $1000 \mathrm{MPa}$ in UTS), neither by precipitation nor by pre-deformation treatments approaches.

\section{Analysis of the dislocation network}

In order to explain the unexpected combination of properties in the oxygen-rich alloys, TEM analysis are conducted on strained samples to study the evolution of the dislocation network in relation with interstitial content (figure 3). 

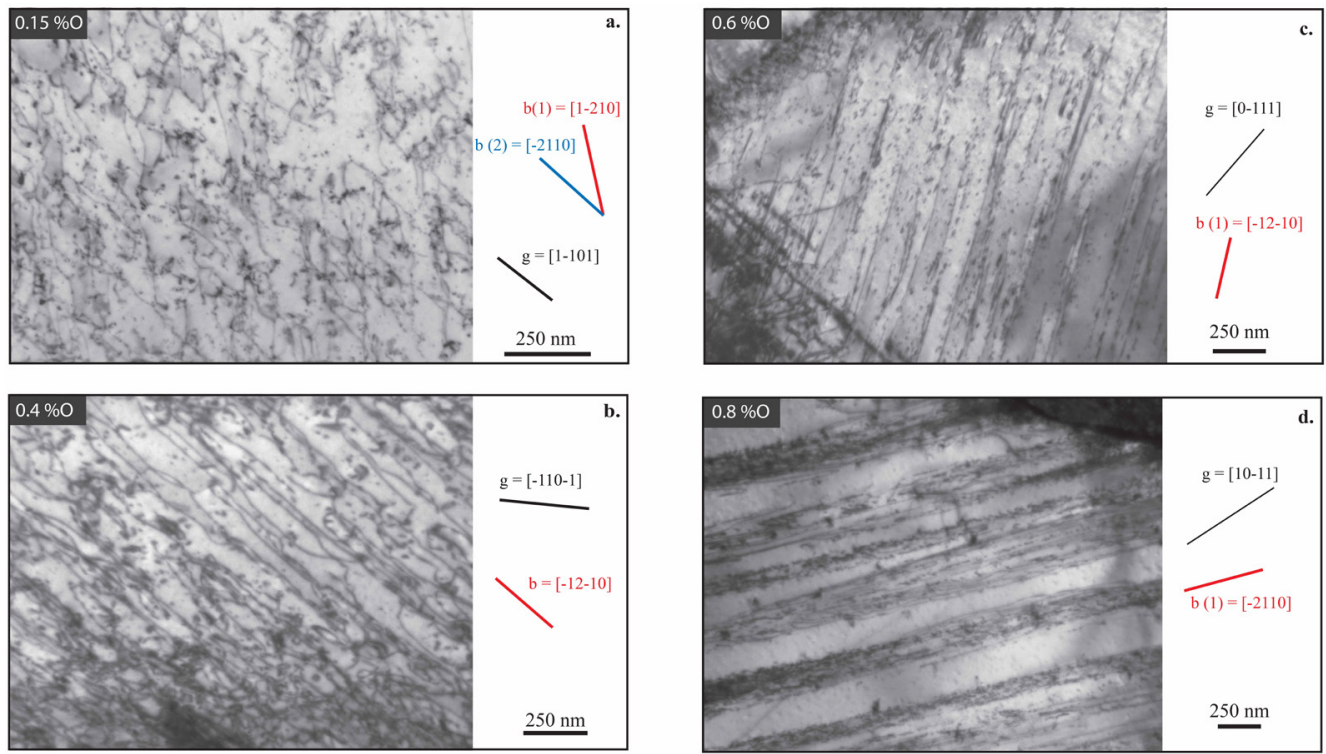

Figure 3: TEM observations of dislocation networks of Ti-4.5\%Zr-X\%O alloys, $X=0.15,0.4,0.6$ and 0.8 (respectively $(a)$, $(b)$, (c), and (d)). Slices were taken in $3 \%$-strained tensile samples, parallel to the tensile axis.

Regardless of the oxygen concentration, screw dislocations control plastic deformation in Ti-Zr-O alloys at room temperature. In low oxygen content materials (figure 1.a), the dislocation network seems entangled, whereas in oxygen-rich alloys (figure 1.d), plastic deformation is no more homogeneous. Furthermore, solute oxygen enhances the pinning effect and the density of debris seems to increase with the interstitial addition, which witnesses the presence of extensive cross slip. In other words, as oxygen content increases, an evolution can be observed from entangled to lined up dislocations, with dislocations becoming straight and hardly aligned along their screw direction. Such behaviour has already been reported [20-21] but with lower oxygen level. Indeed, the appearance of bands is also highlighted, in the most oxygen-rich alloy (figure 1.d), in which dislocations are confined. However, this type of strain localization at microscale should lead to a facilitated material damage during straining, which is not observed. Further investigations will be conducted to apprehend this apparent contradiction between macro- and microscale behaviours.

\section{Conclusion}

In summary, a new Ti-Zr-O alloy family has been designed in order to offer a fully biocompatible alternative for current dental implant materials (Ti-6Al-4V, particularly). The Ashby chart, displaying mechanical strength versus elongation at fracture, over the different titanium alloys families (figure 4), clearly shows that the combination of properties of Ti-Zr-O alloys is unprecedented, especially among the single-phase $\alpha$ titanium alloys. All this conduced to a patent deposit on November 2017 on the Ti-Zr-O family composition [23].

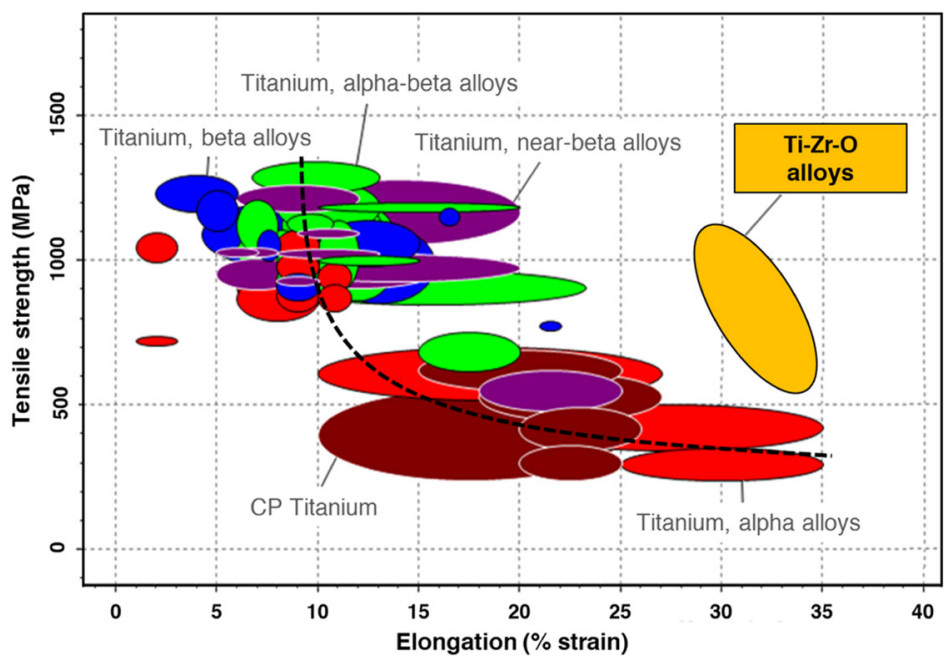

Figure 4: Property map of titanium alloys with location of TiZrO Alloys.

The previous experimental observations may promote the "O based solid solution strengthening approach" opening new tracks in the design strategies, as these preliminary results showed its potential remarkable efficiency for strength/ductility trade-off optimization. The comprehension of the underlying mechanisms supporting these properties is still ongoing.

\section{References}

[1] C. . Gomes et al., "Assessment of the genetic risks of a metallic alloy used in medical implants," Genet. Mol. Biol., vol. 34, no. 1, pp. 116-121, 2011.

[2] A. Langley and C. Dameron, "Modern Metal Implant Toxicity and Anaesthesia.," Australas. Anaesth., pp. 57-65, 2015.

[3] L. Tomljenovic, "Aluminum and Alzheimer's disease: After a century of controversy, is there a plausible link?," J. Alzheimer's Dis., vol. 23 , no. 4, pp. 567-598, 2011.

[4] S.Steinemann, "Corrosion of surgical implants - In vivo and in vitro tests," Adv. Biomater, vol. 1, 1980

[5] K. C. Hari Kumar, P. Wollants, and L. Delacy, “Thermodynamic assessment of the TiZr system and calculation of the NbTiZr phase diagram,” J. Alloys Compd., vol. 206, no. 1, pp. 121-127, 1994.

[6] D. R. N. Correa, F. B. Vicente, T. A. G. Donato, V. E. Arana-Chavez, M. A. R. Buzalaf, and C. R. Grandini, "The effect of the solute on the structure, selected mechanical properties, and biocompatibility of Ti-Zr system alloys for dental applications," Mater. Sci. Eng. C, vol. 34, no. 1, pp. 354-359, 2014.

[7] R. I. Jaffee and I. E. Campbell, “The Effect of Oxygen, Nitrogen, and Hydrogen on Iodide Refined Titanium,” Met. Trans., vol. 185, no. September, pp. 646-654, 1949. 
[8] R. I. Jaffee, H. R. Ogden, and D. J. Maykuth, “Alloys of titanium with carbon, oxygen, and nitrogen,” Trans. AIME - J. Met., vol. 188, pp. 1261-1266, 1950.

[9] W. L. Finlay and J. A. Snyder, "Effects of three interstitial solutes (nitrogen, oxygen, and carbon) on the mechanical properties of high-purity, alpha titanium," Trans. AIME - J. Met., vol. 188 , pp. 277-286, 1950 .

[10] H. Conrad, "Effect of interstitial solutes on the strength and ductility of titanium," Prog. Mater. Sci., vol. 26, pp. 123-403, 1981.

[11] F. Geng, M. Niinomi, and M. Nakai, “Observation of yielding and strain hardening in a titanium alloy having high oxygen content,” Mater. Sci. Eng. A, vol. 528, no. 16-17, pp. 5435-5445,

[12] B. Sun, S. Li, H. Imai, T. Mimoto, J. Umeda, and K. Kondoh, "Fabrication of high-strength Ti materials by in-process solid solution strengthening of oxygen via P/M methods," Mater. Sci. Eng. A, vol. 563, pp. $95-100,2013$.

[13] D. S. Kang, K. J. Lee, E. P. Kwon, T. Tsuchiyama, and S. Takaki, "Variation of work hardening rate by oxygen contents in pure titanium alloy," Mater: Sci. Eng. A, vol. 632, pp. 120-126,

[14] F. Larson and A. Zarkades, Properties of Textured Titanium Alloys, no. June. 1974.

[15] Y. Matayashi and T. Homma, "Effect of Zr addition on recrystallization behavior in rolled Ti-Zr alloys," in TMS Annual Meeting, 2015, pp. 981-988.

[16] B. J. L. Murray and H. A. Wriedt, “The O-Ti ( Oxygen-Titanium ) System,” Bull. Alloy Phase Diagrams, vol. 8, no. 2, pp. 148-149, 1987.

[17] I. I. Kornilov, "Effect of oxygen on titanium and its alloys," Metalloved. i Termicheskaya Obrab. Met., no. 10, pp. 826-829, 1973.

[18] A. E. Medvedev et al., "Microstructure and mechanical properties of Ti-15Zr alloy used as dental implant material," J. Mech. Behav. Biomed. Mater., vol. 62, pp. 384-398, 2016.

[19] K. Nakasuji and M. Okada, "New high strength titanium alloy Ti-10\%Zr for spectacle frames," Mater. Sci. Eng. A, vol. 213, no. 1-2, pp. 162-165, 1996.

[20] A. Kuroda, N. K., and Y. Imamura, “New developed Ti-10Zr Alloy for Consumer Goods Application,” The Sumitomo Search, no. 60, pp. 34-38, 1998.

[21] J. C. Williams, P. P. Tung, and A. W. Sommer, "Influence of Oxygen Concentration on Internal Stress and Dislocation Arrangements in Alpha Titanium,” Metall. Trans., vol. 3, pp. 29792984,1972 .

[22] B. Barkia, J. P. Couzinié, S. Lartigue-Korinek, I. Guillot, and V. Doquet, "In situ TEM observations of dislocation dynamics in $\alpha$ titanium: Effect of the oxygen content," Mater. Sci. Eng. A, vol. 703, no. July, pp. 331-339, 2017.

[23] S. Delannoy and F. Prima, "Ternary Ti-Zr-O Alloys, methods for producing same and associated utilizations thereof," EP 17202971, 2017. 